\title{
Aspectos da reprodução do peixe-porco, Balistes capriscus (Gmelin) (Actinopterygii, Tetraodontiformes, Balistidae) coletado na costa sul do Estado de São Paulo, Brasil
}

\author{
Roberto Ávila Bernardes ${ }^{1}$ \\ June Ferraz Dias ${ }^{1}$
}

\begin{abstract}
Reproductive aspects of the grey triggerfish, Balistes capriscus (Gmelin) (Actinopterygii, Tetraodontiformes, Balistidae) from South São Paulo state coast, Brazil. The monthly analysis of maturity stage frequency suggested that spawning of the grey triggerfish Balistes capriscus (Gmelin, 1788) is annual, total and occurs from November to February in the south of São Paulo State, Brazil. Size at first maturity is $169 \mathrm{~mm}$ for females and $200 \mathrm{~mm}$ for males. Condition factor estimated considering and disconsidering gonad weight ( $\mathrm{K}$ and $\mathrm{K}$ ') showed maximum values related to periods of higher frequency of females at advanced maturity stage. $\Delta K$ was higher in December, January and February, and was related to the maximum frequency of mature females. As $\mathrm{K}$ estimates the gonad condition it could be used as a maturity and breeding season index for this species. The gonadosomatic relation behaved the same as $K$ values.

KEY WORDS. Balistes capriscus, grey triggerfish, reproduction, oocyte development, size at first maturity
\end{abstract}

O peixe-porco Balistes capriscus (Gmelin, 1788) é uma espécie demersal explotada na costa do Estado de São Paulo desde 1967. É encontrado na região tropical e temperada do Atlântico oeste, desde Nova Scotia (Canadá) até a Argentina, bem como na costa sudoeste da África (AIKEN 1975). Existem poucas informações sobre as áreas ocupadas pelos indivíduos jovens. Indivíduos de até 100 milímetros de comprimento furcal são comuns sob tufos de Sargassum e acompanhando objetos à deriva. Pós-larvas de até 10 milímetros de comprimento são capturadas por redes de plâncton entre raízes de Rhizophora mangle. Os adultos são encontrados em profundidades que variam entre 6 e 100 metros (AIKEN 1975).

De acordo com os estudos sobre o comportamento durante a desova, realizados em aquário por GARNAUD (1960), a fêmea do peixe-porco prepara um ninho no substrato, enquanto o macho afasta qualquer animal indesejável. A desova ocorre no fim do dia com dezenas de milhares de ovócitos formando uma massa cinzenta. Após a fecundação, fêmeas e machos protegem os ovos e em 55 horas eclode uma larva de 1,7 mm, que logo assume condição planctônica.

Estudo sobre as fases iniciais dos ciclo de vida de B. capriscus, coletadas na costa sudeste do Brasil, foram realizados por MATSUURA \& KATSURAGAWA (1981, 1985), onde foram tratados osteologia, morfologia, identificação, desenvolvimento e distribuição das larvas.

1) Instituto Oceanográfico, Universidade de São Paulo. Praça do Oceanográfico 191 , 05508-900 São Paulo, São Paulo. E-mail: avila@usp.br, junedias@usp.br 
Este trabalho pretende fornecer subsídios para o entendimento da biologia reprodutiva do peixe-porco e apresenta os resultados de estudos sobre alguns aspectos de sua reprodução: desenvolvimento ovariano; época e tipo de desova; relação peso-comprimento, fator de condição, relação gonadossomática e comprimento médio de primeira maturação gonadal.

\section{MATERIAL E MÉTODOS}

As amostras analisadas neste estudo constituíram-se de 3708 exemplares capturados mensalmente pela frota comercial de parelhas, que opera em águas costeiras na região sul do Estado de São Paulo, entre $24^{\circ} \mathrm{S}$ e $25^{\circ} 15^{\prime} \mathrm{S}$, durante o período de dezembro/84 a dezembro/85 (Fig. 1).

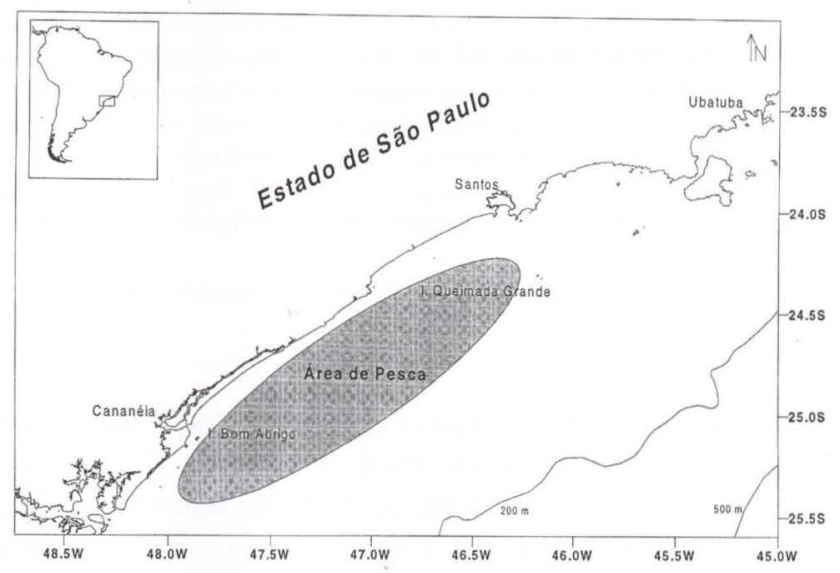

Fig. 1. Localização da área de pesca do peixe-porco.

De cada exemplar foram tomados os dados de comprimento furcal (mm), peso total (g), peso das gônadas (g), identificados o sexo e o estádio de maturação gonadal. As gônadas das fêmeas foram classificadas macroscopicamente através da seguinte escala, descrita em DiAS et al. (1998): (A) imaturas; (B) em maturação; (C) maduras; (D) hidratadas e (E) desovadas. A escala macroscópica adotada para a descrição do desenvolvimento dos testículos foi a seguinte: (A) imaturos apresentavam-se reduzidos a um filamento translúcido, situados logo acima do intestino; (B) em maturação -testículos arredondados, compostos por duas ou três vesículas; (C) maduros - testículos rígidos, amarelados; (D) esvaziados - com aspecto flácido e coloração alaranjada.

Foram considerados indivíduos jovens aqueles em estádio $\mathrm{A}$ e adultos aqueles nos estádios B, C, D e E (fêmeas) ou B, C e D (machos). O comprimento médio de primeira maturação gonadal $\left(\mathrm{L}_{\mathrm{M}}\right)$ foi estimado graficamente, a partir da 
análise da freqüência relativa anual de indivíduos adultos por classe de comprimento para machos e fêmeas.

Neste estudo, ênfase maior é dada às fêmeas, uma vez que se pode considerar os ovários como os órgãos mais apropriados para estudos sobre reprodução das espécies marinhas porque, a partir do reconhecimento dos estádios de maturação hidratado e desovado, pode-se obter informações mais precisas sobre épocas e locais de desova, além do potencial para obtenção do número de descendentes, ou seja, sua fecundidade.

Os ovários foram fixados e conservados em solução de formalina a $4 \%$ neutralizada e processados pela rotina histológica (emblocamento em parafina, cortes com $5 \mu \mathrm{m}$ de espessura e coloração com hematoxilina e eosina) para estudos microscópicos. A análise histológica foi efetuada somente para fêmeas, visando estabelecer uma escala de maturação gonadal menos subjetiva e mais minuciosa e objetiva que a escala macroscópica, a partir da qual se pôde entender o desenvolvimento ovocitário e verificar a freqüência de desova do peixe-porco. Nas preparações permanentes, as medidas foram tomadas de ovócitos adotando-se o núcleo celular como referencial, para as fases em que não ocorre migração do núcleo.

A relação entre o peso total $\left(W_{t}\right)$ e o comprimento furcal $\left(L_{F}\right)$ dos indivíduos para sexos agrupados e separados, a cada mês, foi ajustada aos dados seguindo a expressão: $W_{t}=a \times L_{F}{ }^{b}$, onde a é o coeficiente linear e b o coeficiente angular.

Os coeficientes linear e angular foram estimados pelo método dos mínimos quadrados e comparados mediante teste-t, para verificar possíveis diferenças entre os sexos.

As variações individuais da relação peso-comprimento foram estudadas através do fator de condição $\mathrm{K}$, sendo utilizadas as expressões: $K=W_{\mathrm{t}} / L_{F}{ }^{b}$, para machos e fêmeas; e $K^{\prime}=W_{c} / L_{F}{ }^{b}$, somente para fêmeas, onde $W_{\mathrm{t}}$ é o peso total e $W_{\mathrm{c}}$ é o peso do corpo sem as gônadas. Foram calculados os valores médios mensais de K e K', bem como a variação de ambos: $\Delta \mathrm{K}=\mathrm{K}-\mathrm{K}$ ', para fêmeas.

Calculou-se, também, a relação gonadossomática $(R G S)$ de cada exemplar fêmea, a cada mês, a fim de relacionar sua variação com o período e freqüência de desova, através da equação: $R G S=W_{g} / W t$, onde $W_{g}$ é o peso das gônadas, e $W_{t}$ é o peso total do indivíduo.

\section{RESULTADOS}

\section{Anatomia microscópica dos ovários}

A análise microscópica dos ovários de Balistes capriscus permitiu verificar que os mesmos são revestidos externamente por tecido conjuntivo denso que emite lamelas, dividindo o ovário em compartimentos onde as células germinativas são sustentadas por um tecido conjuntivo frouxo (estroma ovariano).

As células germinativas observadas apresentaram um processo de desenvolvimento que pôde ser descrito em cinco fases:

\section{Ovócitos Basófilos do Estoque de Reserva (não vitelogênicos) (Fase II)}

Apresentam-se nitidamente individualizados, com diâmetro variando de 75 a $94 \mu \mathrm{m}$ (média $=84,5 \mu \mathrm{m})$; núcleo excêntrico; nucléolos múltiplos, membrana celular nítida, grande volume citoplasmático fortemente basófilo. 


\section{Ovócitos com Alvéolos Corticais (Fase III)}

Apresentam nítida vacuolização do citoplasma, representando a deposição de lipídios no ovócito junto à membrana celular. $\mathrm{O}$ diâmetro variou de 220 a 242 $\mu \mathrm{m}($ média $=231 \mu \mathrm{m})$; apresenta uma membrana acelular envolvendo-o denominada membrana vitelina ou pelúcida, justaposta à membrana citoplasmática. Externamente à membrana vitelina ocorre uma camada de células foliculares.

\section{Ovócitos em Vitelogênese Lipídica e Protéica (Fase IV)}

Caracteriza-se pelo maior número de vesículas lipídicas e sua coalescência, e pela deposição de grãos de proteína. A membrana vitelina apresenta-se mais nítida. O diâmetro variou de 319 a $340 \mu \mathrm{m}$ (média $=329,5 \mu \mathrm{m})$.

\section{Ovócitos em Vitelogênese Completa (Fase V)}

Não se percebem mais a predominância das vesículas lipídicas nesta fase. $\mathrm{O}$ citoplasma apresenta um aspecto mosaico, pela presença de elevado número de plaquetas acidófilas. O núcleo perde a forma esférica, mantendo os nucléolos periféricos. O diâmetro varia de 324 a $374 \mu \mathrm{m}($ média $=350 \mu \mathrm{m})$.

\section{Ovócitos Hidratados (Fase VI)}

Apresentam coloração rósea e uma aparência gelatinosa do citoplasma quando coradas pelo método citado. Os ovócitos nesta fase se deformam quando submetidos à técnicas de desidratação da rotina histológica. O diâmetro varia de 360 a $399 \mu \mathrm{m}$ (média = 379,5 $\mu \mathrm{m})$.

Nesta fase os ovócitos estão prontos para serem liberados para o meio externo, para serem fecundados. Quando ocorre a desova, o ovócito deixa o ovário com a membrana vitelina, restando a camada de células foliculares. Esta sofrerá contração passando a ser denominada folículo pós-ovulatório.

Em alguns ovários foi observada a presença de ovócitos em processo de atresia. O desenvolvimento é interrompido e o ovócito é desestruturado por autólise ou fagocitose, sendo posteriormente absorvido. Este processo pode ocorrer devido a alterações metabólicas.

O estudo histológico dos ovários em diversas fases de desenvolvimento permitiu verificar a presença de praticamente dois lotes de células, ou seja, as do estoque de reserva (fase II) e aquelas em outra fase (fase III, IV, V ou VI), o que caracteriza o desenvolvimento sincrônico dos ovócitos e sugere desova do tipo total.

\section{Período de desova e comprimento médio de primeira maturação gonadal}

O período reprodutivo foi estimado pela ocorrência de fêmeas com gônadas maduras, hidratadas e desovadas, e de machos com testículos maduros e esvaziados na distribuição de freqüência mensal dos estádios de maturação gonadal (Fig. 2). As fêmeas com ovários nos estádios $\mathrm{C}$ de maturação, indicativos de atividade reprodutiva, ocorreram com maior freqüência nos meses de novembro, dezembro, janeiro e março, enquanto que os machos com testículos no estádio $\mathrm{C}$ ocorreram entre novembro e fevereiro. Fêmeas com ovários nos estádios D (hidratado) e E (desovado), indicadores seguros de desova, foram encontradas entre novembro e março (Fig. 2). 

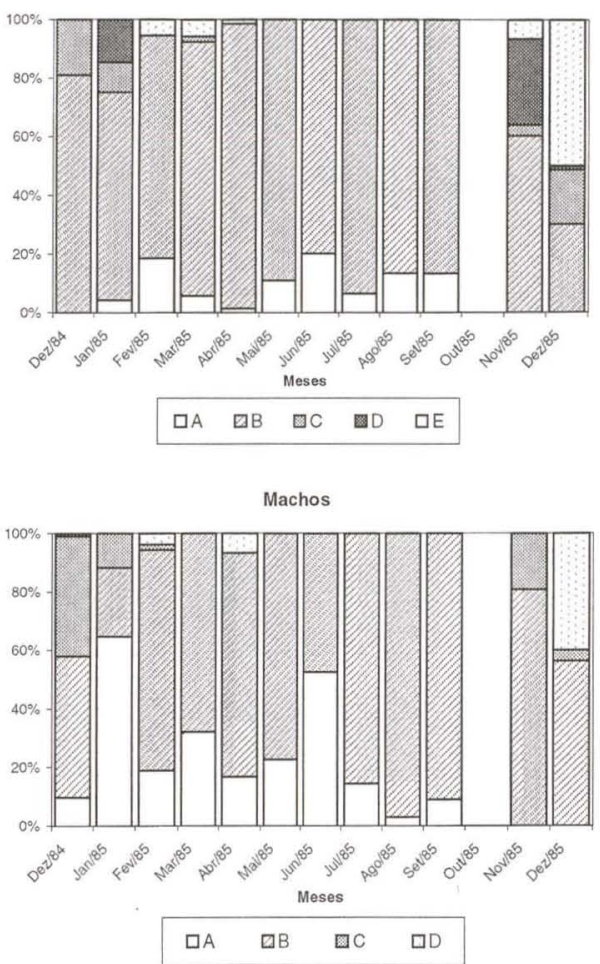

Fig. 2. Variação mensal dos estádios de maturação gonadal de fêmeas $(N=1240)$ e machos $(\mathrm{N}=814)$.

O comprimento médio de primeira maturação gonadal, corresponde ao comprimento furcal de $169 \mathrm{~mm}$ para as fêmeas e $200 \mathrm{~mm}$ para os machos. Durante a amostragem foi verificado que a menor fêmea adulta mediu $182 \mathrm{~mm}$ e que o menor indivíduo adulto macho mediu $168 \mathrm{~mm}$ de comprimento furcal. Esses valores revelam uma ampla variação dos valores de $\mathrm{L}_{\mathrm{M}}$, principalmente para os machos.

\section{Relação Peso-Comprimento, Fator de Condição e Relação Gonadossomática}

A relação peso-comprimento foi representada pelas seguintes equações: fêmeas: $\mathrm{W}_{\mathrm{t}}=0,000003 \mathrm{Lf}^{3,340} ; \mathrm{r}^{2}=0,965 ; \mathrm{n}=1240$; machos: $\mathrm{W}_{\mathrm{t}}=0,000005 \mathrm{Lf}^{3,265} ; \mathrm{r}^{2}=0,969 ; \mathrm{n}=814$; sexos agrupados: $\mathrm{W}_{\mathrm{t}}=0,000004 \mathrm{Lf}_{\mathrm{f}}^{3,299} ; \mathrm{r}^{2}=0,968 ; \mathrm{n}=1654$.

$O$ teste- $t$ indicou diferenças significativas $(p=0,05)$ entre as relações de machos e fêmeas.

$\mathrm{O}$ fator $\mathrm{K}$ de condição apresentou variações acentuadas durante o período estudado, com valores médios mensais mostrados nas figuras 3 e 4 .

As fêmeas apresentaram valores altos nos meses de dezembro a abril e baixos de junho a setembro, havendo uma tendência a aumentar a partir de setembro. Para os machos os valores foram altos de dezembro a maio e baixos de junho a setembro, apresentando variação semelhante à das fềmeas. 

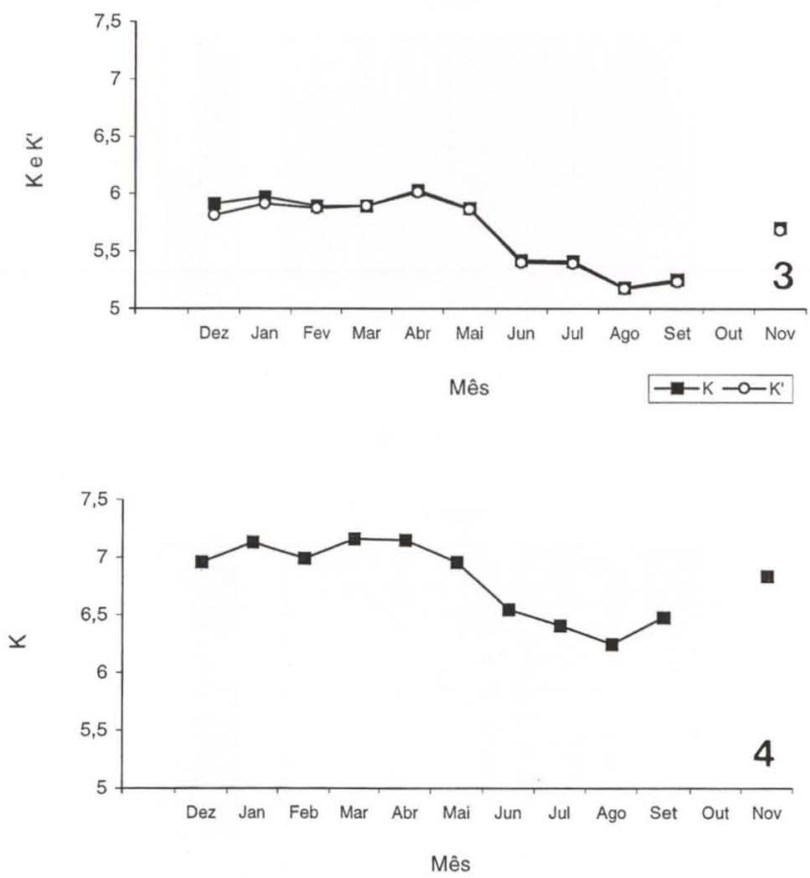

Figs 3-4. Variação mensal do valor médio do fator de condição $K$ de $B$. capriscus. (3) Fêmeas $(\mathrm{N}=1240) ;(4)$ machos $(\mathrm{N}=814)$.

Os fatores $\mathrm{K}$ e K' apresentaram a mesma tendência em sua variação anual. Observou-se períodos em que o $\Delta \mathrm{K}$ apresentou valores mais elevados, como nos meses de dezembro a abril, coincidindo com o período de maior ocorrência de fêmeas maduras (Fig. 5).

A relação gonadossomática (RGS) mostrou-se elevada nos meses de novembro a janeiro e baixa no restante do ano (Fig. 6), apresentando a mesma tendência do $\Delta \mathrm{K}$ em sua variação anual.

\section{DISCUSSÃO}

Em geral, os peixes apresentam dois tipos básicos de desenvolvimento ovocitário. No primeiro tipo (sincrônico), existem dois lotes de células germinativas nos ovários, um de células jovens que representam o estoque de reserva e outro de ovócitos em alguma fase da maturação. Nesse tipo, os indivíduos podem eliminar todos os ovócitos ao mesmo tempo ou em curto período de tempo, caracterizando na desova total, ou em tempos mais longos, caracterizando desova parcelada. No desenvolvimento assincrônico, existem no ovário, além de células do estoque de reserva, vários lotes de células germinativas em diferentes fases de desenvolvimento. A desova, neste caso, pode ocorrer fracionadamente ou quando todos os lotes de ovócitos atingirem a fase madura (VAZZOLER 1996). Os resultados obtidos para o peixe-porco sustentam a hipótese de desenvolvimento sincrônico e desova do tipo total. 

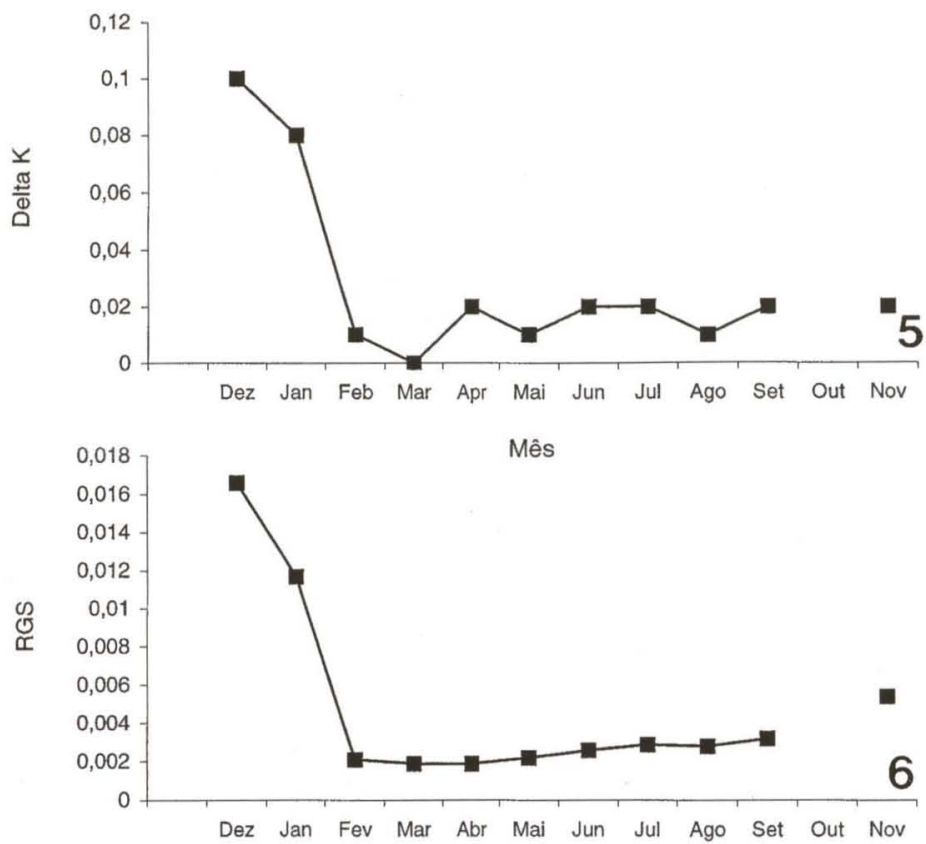

Figs. 5-6. (5) Variação mensal do valor médio de Delta $K$ de fêmeas $(N=1240)$; (6) variação mensal do valor médio da relação gônadossomática - RGS, de fêmeas $(N=1171)$.

A maioria das escalas de maturidade gonadal para peixes teleósteos está baseada em critérios macroscópicos tais como forma, tamanho, cor, intensidade da vascularização sangüínea, visibilidade, tamanho e aspecto dos ovócitos etc. (YAMAGUTI 1967; VAZZOLER 1971, 1981). Estas escalas possuem a vantagem da rápida classificação de um grande número de exemplares. Entretanto, tem-se demonstrado que os critérios macroscópicos, além de subjetivos, podem ser muito variáveis e mascarar alguns processos que ocorrem no interior das gônadas que não são perceptíveis a olho nu (DiAs et al. 1998).

A escala macroscópica de maturação gonadal adotada neste estudo constituiu-se de cinco estádios para fêmeas e quatro estádios para machos. Apesar dos ovários apresentarem alterações morfológicas marcantes, a escala macroscópica de maturidade utilizada contém descrições que puderam caracterizar de forma objetiva os estádios aqui considerados. Porém, para os indivíduos machos, ocorreram poucas alterações na forma, tamanho e coloração dos testículos e a escala macroscópica de maturidade adotada foi apenas satisfatória.

Para as fềmeas, no início da vitelogênese, os ovócitos da fase II começam a apresentar um rápido aumento de volume até atingirem a fase $\mathrm{V}$ com o triplo do diâmetro inicial, devido ao vitelo e vacúolos produzidos e armazenados no seu interior. Porém, a comparação entre o diâmetro dos ovócitos nas fases V (vitelogênese 
completa) e VI (hidratados) torna claro que o processo de hidratação não aumenta consideravelmente o volume do ovoplasma desta espécie. Este fato pode ser explicado pois, diferentemente do que ocorre com espécies que apresentam ovos pelágicos, os ovos de Balistes capriscus são bentônicos, e uma das funções atribuídas à hidratação do ovócito é o posterior auxílio para manutenção do ovo na coluna de água. Pelo mesmo motivo, também não ocorrem gotas de óleo nos ovócitos e ovos.

As células germinativas iniciais (fase I) não foram observadas nas preparações permanentes dos ovários cortados, porém são células iniciais do desenvolvimento dos ovócitos (ovogônias) que se encontram reunidas em ninhos junto à teca interna (CHAVES \& VAZZOLER 1984). Como ainda não é conhecida a anatomia microscópica dos ovários do peixe-porco, a não observação de ovogônias pode ser devida três causas: a uma concentração dos ninhos em áreas restritas e não cortadas dos ovários; ou a que ovogônias possam ser produzidas a partir das células dos folículos pós-ovulatórios (FOUCHER \& BEAMISH 1980); ou ainda que células lamelares indiferenciadas possam se diferenciar em ovogônias em curto espaço de tempo. Nos dois últimos casos sua observação seria inviabilizada num material coletado com freqüência mensal, como foi o caso deste trabalho.

A análise da ocorrência temporal das distintas fases de maturação sugere que o estádio de maturidade $\mathrm{C}$ inicia-se em outubro e que a passagem para o estádio $\mathrm{D}$ ocorreria em curto período, cerca de um mês.

A baixa freqüência de indivíduos no estádio $\mathrm{D}$ (hidratados) e $\mathrm{E}$ (desovados) nas amostras, provavelmente se deve ao comportamento reprodutivo da espécie, ou seja, ao deslocamento dos reprodutores para áreas mais profundas para construção e permanência nos ninhos de desova, tornando-se menos acessíveis à pesca.

Em nosso estudo, a freqüência dos diferentes estádios de maturação mostrou maior ocorrência de indivíduos maduros nos meses de novembro a março, com pico em dezembro. Fêmeas no estádio D (hidratadas) e E (desovadas) foram observadas de novembro até abril. Estes resultados indicam um período relativamente curto de desova, iniciando-se provavelmente em outubro, devido à ocorrência de indivíduos no estádio $\mathrm{D}$ em novembro, e máxima atividade reprodutiva em dezembro. OFORIDANSON (1990) encontrou semelhante resultado quanto ao período reprodutivo para B. capriscus capturado em Ghana.

Com relação ao comprimento médio de primeira maturação, embora o menor comprimento furcal do indivíduo adulto registrado tenha sido de $168 \mathrm{~mm}$ para machos e de $182 \mathrm{~mm}$ para fêmeas, o comprimento estimado ( $\mathrm{L}_{\mathrm{M}}$ ) foi $169 \mathrm{~mm}$ para as fêmeas e $200 \mathrm{~mm}$ para os machos. Foi estimado que todos os indivíduos (machos e fêmeas) com comprimento furcal a partir de $210 \mathrm{~mm}\left(\mathrm{~L}_{100}\right)$ estariam participando da reprodução. Na Costa do Marfim, o comprimento furcal de primeira maturação estimado, foi $150 \mathrm{~mm}$, enquanto que no Senegal e Golfo da Guiné foi $135 \mathrm{~mm}$ (CAVĖRIVIÉRE et al. 1981), e nas águas costeiras de Ghana foi $145 \mathrm{~mm}$ para as fêmeas (OFORI-DANSON 1990). Estas diferenças podem refletir condições ambientais regionais e específicas.

Pôde-se verificar uma grande diferença entre o valor estimado de LM para os machos em relação ao das fêmeas. Neste caso, o valor do comprimento médio 
de primeira maturação gonadal para os machos deve ser tomado com reservas, uma vez que pode ter ocorrido a classificação de indivíduos já adultos (em estádio B de maturação gonadal) como imaturos (estádio $\mathrm{A}$ ), em decorrência da pequena variação em tamanho apresentada pelos testículos nessas fases de desenvolvimento.

Apesar da necessária cautela quando do exame dos valores de $\mathrm{L}_{\mathrm{M}}$ para os machos, foram detectadas diferenças significativas nos valores dos coeficientes da relação peso-comprimento entre machos e fêmeas, indicando um crescimento diferencial dos machos em relação ao das fềmeas, sugerindo que estes apresentem crescimento mais lento e chegando mais tarde à maturidade.

Na maioria dos casos existe uma relação entre o ciclo reprodutivo e o fator de condição. As variações do valor de K têm sido utilizadas como medida de vários processos biológicos como modificações das reservas de gordura, adequação ao ambiente e desenvolvimento gonadal (LE CREN 1951). Em algumas espécies o fator $\mathrm{K}$ é mais baixo nos peixes imaturos do que nos maduros durante os meses de desova. A medida em que os indivíduos vão desovando os valores do fator de condição caem rapidamente (BAGENAL 1957).

Nossos resultados sobre a variação de K e K' apresentaram concordância entre os valores máximos e os picos de ocorrência de fêmeas com ovários maduros, e seus valores mínimos com a queda da freqüência de indivíduos maduros, logo após o período reprodutivo. Estas variações poderiam ser explicadas pelo acúmulo de reservas no corpo e nas gônadas e posterior utilização durante a maturação dos ovócitos e desova. As maiores diferenças encontradas entre os valores de $\mathrm{K}$ e $\mathrm{K}$ ' ocorreram no período de maior atividade das gônadas, indicando que $\Delta \mathrm{K}$ seria um bom estimador da condição das gônadas, identificando os períodos de máxima maturidade.

A relação gonadossomática possui a vantagem de fornecer um valor objetivo da condição da gônada e, no caso de espécies com desenvolvimento sincrônico dos ovócitos e desova total, como o peixe-porco, pôde ser utilizada como uma medida quantitativa do estádio de maturidade gonadal.

A análise conjunta dos resultados indica que Balistes capriscus na costa do Estado de São Paulo, apresenta atividade reprodutiva entre novembro e abril, e desova no período que compreende os meses de novembro a fevereiro, com pico em dezembro. MATSUURA \& KATSURAGAWA (1981) encontraram larvas e juvenis do peixe-porco somente no verão, especialmente nos cruzeiros de pesquisa realizados em janeiro, reforçando os resultados aqui descritos sobre o período reprodutivo. Semelhante resultado também foi encontrado para a espécie na costa da África (CAVĖRIVIÉRE et al. 1981).

AGRADECIMENTOS. Ao Dr Noriyoshi Yamaguti e à Dra Anna Emília Amato de Moraes Vazzoler (in memorian), do Instituto Oceanográfico da Universidade de São Paulo, pelas importantes sugestões durante os estudos sobre esta espécie e à FAPESP pela concessão de bolsa e financiamento (R.A.B.). Agradecemos as valiosas contribuições de dois revisores anônimos.

Revta bras. Zool. 17 (3): 687 - 696, 2000 


\section{REFERÊNCIAS BIBLIOGRÁFICAS}

AIKEN, K.A. 1975. The biology, ecology and bionomics of the Triggerfishes, Balistidae. ICLARM-7, Phillipines.

BAgENAL, T.B. 1957. The breeding and fecundity of long rough dab Hippoglossoides platessoides (Fabr.) and associated cycle in condition. Jour. Mar. Biol. Ass. U.K. 36: 339-375.

CAvĖriviére, A.; M. Kulbicki; J. KonAn \& F. Gerlotto. 1981. Bilan des connaissances actuelles sur Balistes capriscus dans Golfe de Guineé. Doc. Sci. Centre Rech. Océan. Abidjan., Vol. 12, no. 1.

ChaVES, P.T. DA C. \& A.E.A. DE M. VAzzoler. 1984. Aspectos biológicos de peixes amazônicos: II anatomia microscópica de ovários, escala de maturação e tipo de desova das espécies do gênero Semaprochilodus. Rev. Brasil. Biol. 44 (3): 347-359.

Dias, J.F.; E. Peres-Rios; P. DE T. DA C. Chaves \& C.L.D.B. Rossi-wongtschowski. 1998. Análise macroscópica dos ovários de teleósteos: problemas de classificação e recomendações de procedimentos. Rev. Brasil. Biol. 58 (1): 55-69.

FoucheR, R.P. \& R.J. BEAmish. 1980. Production of nonviable oocytes by Pacific hake (Merluccius productus). Can. Jour. Fish. Aquat. Sci. 37: 41-48.

Garnaud, J. 1960. La ponde, l'eclosion, la larve du balistes Balistes capriscus (Linné 1758). Bull. Inst. Oceanogr., Monaco, (1169): 1-6.

LE CREN, E.D. 1951. The length-weight relationship and seasonal cycle in gonad weight and condition in perch (Perca fluviatilis). Jour. An. Ecol. 20 (2): 201-219.

Matsuura, Y. \& M. Katsuragawa. 1981. Larvae and juveniles of grey triggerfish, Balistes capriscus, from Southern Brazil. Jap. Jour. Ichthyol. 28 (3): 267-275.

. 1985. Osteological development of fins and their supports of larval grey triggerfish, Balistes capriscus. Jap. Jour. Ichthyol. 31 (4): 411-421.

Ofori-Dananson, P.K. 1990. Reproductive ecology of the triggerfish, Balistes carpiscus from the Ghanaian coastal waters. Trop. Ecol. 31 (1): 1-11.

VAZZol.ER, A.E.A. DE M. 1971. Diversificação fisiológica e morfológica de Micropogon furnieri (Desmarest, 1822) ao sul de Cabo Frio, Brasil. Bol. Inst. oceanogr., São Paulo, 20 (2): 1-70.

- 1981. Manual de métodos para estudos biológicos sobre populações de peixes. Crescimento e Reprodução. Brasília, CNPq/Programa Nacional de Zoologia, 108p.

- 1996. Biologia da reprodução de peixes teleósteos: teoria e prática. Maringá, EDUEM/SBI, 169p.

Y^m^GUT1, N. 1967. Desova da pescada foguete Macrodon ancylodon. Bol. Inst. oceanogr., São Paulo, 16 (1): 101-106.

Recebido em 28.X.1999; aceito em 23.VIII.2000 